\title{
8
}
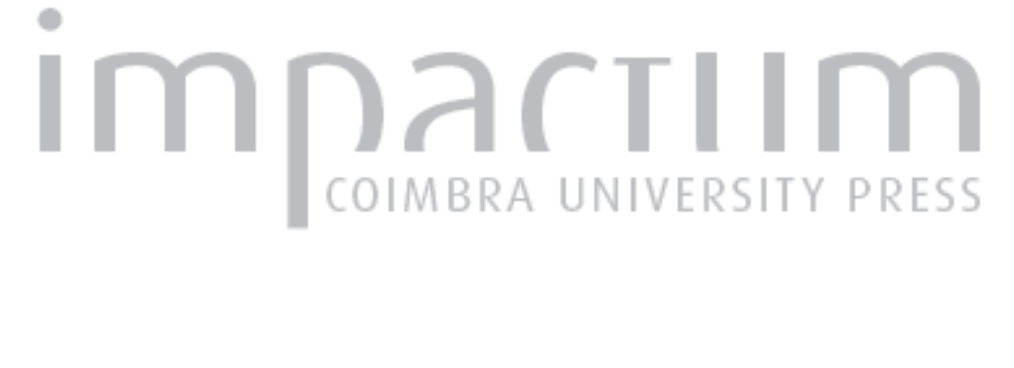

\section{Arqueologia das cidades de Beja: um projecto da ciência da Epiderme das terras que emergem}

\author{
Autor(es): $\quad$ Lopes, Maria Conceição
}

Publicado por: Faculdade de Letras da Universidade de Coimbra

URL persistente:

URI:http://hdl.handle.net/10316.2/37860

DOI:

DOI:http://dx.doi.org/10.14195/1647-8657_49_4

Accessed : $\quad$ 26-Apr-2023 09:56:57

A navegação consulta e descarregamento dos títulos inseridos nas Bibliotecas Digitais UC Digitalis, UC Pombalina e UC Impactum, pressupõem a aceitação plena e sem reservas dos Termos e Condições de Uso destas Bibliotecas Digitais, disponíveis em https://digitalis.uc.pt/pt-pt/termos.

Conforme exposto nos referidos Termos e Condições de Uso, o descarregamento de títulos de acesso restrito requer uma licença válida de autorização devendo o utilizador aceder ao(s) documento(s) a partir de um endereço de IP da instituição detentora da supramencionada licença.

Ao utilizador é apenas permitido o descarregamento para uso pessoal, pelo que o emprego do(s) título(s) descarregado(s) para outro fim, designadamente comercial, carece de autorização do respetivo autor ou editor da obra.

Na medida em que todas as obras da UC Digitalis se encontram protegidas pelo Código do Direito de Autor e Direitos Conexos e demais legislação aplicável, toda a cópia, parcial ou total, deste documento, nos casos em que é legalmente admitida, deverá conter ou fazer-se acompanhar por este aviso.

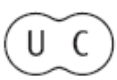


CONIMBRIGA

C)

CN N N

INSTITUTO DE ARQUEOLOGIA

VOLUME XLIX • 2010

FACULDADE DE LETRAS 
MARIA CONCEIÇÃO LOPES

Universidade de Coimbra/CEAUCP

\section{ARQUEOLOGIA DAS CIDADES DE BEJA UM PROJECTO \\ DA CIÊNCIA DA EPIDERME DAS TERRAS QUE EMERGEM \\ "Conimbriga" XLIX (2010) p. 69-86}

Resumo: Partindo de uma síntese sobre os caminhos da arqueologia até se tornar ciência e do Projecto Arqueologia das cidades de Beja, o qual enquadra as escavações no forum da cidade de Pax Iulia (Beja - Portugal), questiona-se a prática arqueológica da preservação pelo registo particularmente em Portugal, na actualidade. Conceptualização, préstimo científico e social e metodologia são, portanto, equacionados.

ABSTRACT: Partant d'une synthèse concernant le parcours de l'archéologie jusqu'à ce que cette approche devienne science et du projet Archéologie des villes de Beja (qui inscrit les fouilles dans le Forum de la ville de Pax Iulia, Beja - Portugal), nous nous interrogeons sur la pratique de l'archéologie dans le monde actuel, en particulier au Portugal. Il s'agit de mettre en débat la conceptualisation, l'importance scientifique e social e la méthodologie de cette archéologie de la préservation pour l'enregistrement.

Conimbriga, 49 (2010) 69-86 
(Página deixada propositadamente em branco) 


\section{ARQUEOLOGIA DAS CIDADES DE BEJA UM PROJECTO DA CIÊNCIA DA EPIDERME DAS TERRAS QUE EMERGEM}

Dotada de métodos rigorosos para executar a pesquisa e analisar os elementos que constituem a documentação que permite abordar o seu objecto de estudo e de legislação que enquadra e regula o seu trabalho, a Arqueologia afirma-se hoje como a ciência melhor apetrechada para a análise das sociedades do passado e do seu percurso.

Porém, considerando os debates em que actualmente se encontra envolvida, parece não terem ainda encontrado uma definição sobre a natureza das conclusões que se podem deduzir da investigação arqueológica, particularmente daquelas que se relacionam com a cultura material e com a informação e importância que esta assume na construção do discurso da Arqueologia..

Os arqueólogos sempre foram mais unânimes nas questões relacionadas com o método que com aquelas que envolvem conceitos teóricos e posicionamentos epistemológicos. Um breve percurso à evolução da disciplina permite-nos constatar que só em circunstâncias muito particulares a técnica e a reflexão, o modo e as coisas, são objecto de um questionamento integrado.

Fixando o interesse pelo estudo do passado na curiosidade em descobrir a inédita imagem da terra que as novas descobertas proporcionavam e na construção de conhecimento novo e consequente processo de recomeço do mundo em que os eruditos renascentistas se empenharam na pesquisa dos monumentos e objectos do passado, que príncipes, papas, nobres e burgueses acumulavam em colecções, surge como a demonstração das materialidades e memória de um passado grandioso que havia que recuperar e preservar, "démolir les monuments

Conimbriga, 49 (2010) 69-86 
de Rome n'est rien d'autre que de diminuer l'excellence de la ville elle-même et de tout l'univers"

Apesar de ser neste contexto humanista que se situa a libertação dos vestígios do passado da categoria de desperdícios da história da humanidade que o Cristianismo lhes fixou e a Idade Média lhes outorgou, o termo Arqueologia só foi introduzido no vocabulário moderno no final do século XVII, por Jacques Spon, um médico, antiquário e erudito francês, originário de Lyon e será apenas nas escavações sistemáticas iniciadas nas cidades soterradas pelo Vesúvio, no segundo quartel do século XVIII, que se situa o momento decisivo da constituição da Arqueologia como ciência.

A desenfreada corrida aos objectos e modo como se exumavam os vestígios, os quais emergindo carregados de informação sobre o passado das sociedades confrontavam as fontes escritas até aí hegemónicas na investigação de carácter histórico, suscitou na comunidade culta e erudita da época uma forte reprovação. O desabafo de Goethe, "é deplorável que as escavações não sejam feitas com um plano regular", proferido em Pompeia ao observar o modo como o Engenheiro Alcubierre, que a mando do Rei de Espanha Carlos III esventrava a cidade em busca de objectos para a corte, exprime a exigência de uma escavação metódica. e a consciência de que sem uma geometria de referência dos vestígios arqueológicos grande parte do seu valor informativo perder-se-ia.

Winckelmann, companheiro de Goethe na visita às escavações das "cidades do Vesúvio", defendia a necessidade de um registo espacial do sítio e o acompanhamento de todas as descobertas, de modo a pôr fim à simples busca de preciosidades e de objectos para colecção, apenas pelo seu valor material, estabelecendo, também, para a Arqueologia, a fórmula erudita máxima da época: observar, registar e publicar.

Nestes princípios se funda a Arqueologia como ciência metódica e se concretiza a ruptura epistemológica com a prática predadora dos objectos do passado. À Comissão de Ciências e das Artes do Exército do Oriente que acompanhou Napoleão Bonaparte no Egipto, a qual decidiu abdicar do nivelamento do rio Nilo em benefício da Arqueologia, poderá reconhecer-se o pioneirismo do trabalho segundo

1 Nam demoliri Urbis monumenta nihil aliud est quam ipsius Urbis et totius orbis ecelentiam diminuere. ", afirmação inscrita em nota papal. No ano1439, durante o pontificado de Eugénio IV; citado por REVEST, Clémence, Se souvenir de Rome: Humanisme et pedagogie de la Mémoire dans l'Italie du XVe siècle, Paris, 2007, p. 5

Conimbriga, 49 (2010) 69-86 
uma metodologia de registo dos vestígios do passado e os princípios proferidos por Winckelmann

A universalização da Arqueologia no século XIX, a descoberta da Pré-História e a desconfiança da leitura literal da bíblia, a respeito das origens do Homem ${ }^{2}$, reforçaram o valor superlativo dos vestígios materiais no estudo sistemático do Homem e do seu passado e determinaram a aplicação de profundas mutações metodológicas na exumação dos vestígios. Porém, a espectacularidade das descobertas na Grécia e no Próximo Oriente, seriam uma séria contrariedade para que a Arqueologia se libertasse da ideia de actividade fascinante de busca e colecção de objectos/tesouros do passado.

Ao mesmo tempo, a ligação do património com os estados em formação no século XIX na afirmação dos ideais de nação, "proporcionando a prova de um passado material fundador"’3 ou a colaboração ao serviço da ideologia dos estados totalitários do século $\mathrm{XX}$, são perturbações fortes no percurso evolutivo da Arqueologia e constituirão sérios obstáculos à sua afirmação como ciência.

Será apenas no decurso do século XX, sobretudo depois da Primeira Guerra, que se dará a definitiva ruptura da Arqueologia com a tradição que a definia como um método e técnica de colecção de objectos e monumentos do passado. Estruturada no princípio de que cada cultura é um conjunto de normas que regulam o comportamento humano, a Arqueologia evolui centrada na construção seriações de objectos para tipificar as culturas

A afirmação da Arqueologia como disciplina científica, cujo objectivo é estudar e conhecer a história da humanidade desde as origens até ao presente, com base nos vestígios materiais que se preservaram mas que o tempo ocultou, ocorre com a "Nova Arqueologia". Tendo como campo epistemológico as sociedades pretéritas, a Nova Arqueologia contrapõe à Arqueologia cultural uma arqueologia mais científica que embora dialogante com a Antropologia ou a História se distancia delas

2 O dinamarquês Christian Thomsen, num livro publicado em 1836, apresentou um periodização para a Pré-história: idade da Pedra Lascada, idade da Pedra Polida e idade do ferro. Essa classificação foi mais tarde substituída pela do inglês John Lubbock, que definiu o Paleolítico, o Neolítico ao que Thomsen denominara idade da Pedra Lascada e idade da Pedra Polida.

3 KOSSINA, Gustav. (1911). Die Herkunft der Germanen. Leipzig: Kabitzsch.

Conimbriga, 49 (2010) 69-86 
pelo facto de sustentar os seus estudos nos restos materiais dessas sociedades e culturas.

Nesta Arqueologia mais científica o estabelecimento do método estratigráfico de escavação $0^{4}$, o desenvolvimento de modos de interpenetração com outras ciências em cujo diálogo se desenvolveram e adaptaram métodos de prospecção, e métodos de análise com recurso ao uso dos meios informáticos e da estatística, métodos de datação como o C14, e se ajustaram protocolos de questionamento e meios de prova, os quais, entre outros, constituirão as mais radicais mutações metodológicas e teóricas que sustentam a afirmação da Arqueologia como ciência.

Desembaraçada dessa ideia de aventura fascinante em busca de tesouros do passado que a marcaram na sua origem, no século $\mathrm{XV}$, aprofundada com a visão romântica de caça ao tesouro dos séculos XVIII e XIX, desenvolvida nas escavações de Pompeia e Herculano, estas últimas descritas por Charles de Bosses como sendo feitas por exploradores correndo perigos, descendo a mais de $15 \mathrm{~m}$, para retirar vestígios intactos à luz das tochas e pelas descobertas nas pirâmides do Egipto e nas cidades da Grécia e da Mesopotâmia, a Arqueologia esforça-se, no presente, por apagar a presunção, ainda muito comum entre os académicos, de ser uma disciplina técnica que acede aos objectos e monumentos do passado, com vista a servir o discurso da História.

No mundo americano, do norte e do sul, a Arqueologia fez um percurso fortemente vinculada com a Antropologia e, por isso, evoluiu com maior liberdade relativamente aos factos datados e com grande independência relativamente à História. A evidência de que o tempo do facto arqueológico não é o do tempo da História esclarecem que a Arqueologia e a História se relacionam por vínculos distintos dos de dependência.

No contexto das escolas europeias, onde a construção da Arqueologia se fez como disciplina variante da História, as academias e os académicos têm exigido à Arqueologia um sistemático trabalho de prova de que o estudo do passado escapa ao monopólio da História e um esforço redobrado na afirmação do seu espaço como disciplina que se ocupa da dinâmica do processo de evolução das sociedades, cujos testemunhos

4 A Harris Matrix inventada em 1973 por Edward C. Harris, permitiu aos arqueólogos dispor de uma ferramenta que permite um mais rigoroso registo das ocorrências da escavação. Edward C. Harris, "Principles of Archaeological Stratigraphy", 40 figs. 1 pl. 136 pp. London \& New York: Academic Press. Second edition 1989.

Conimbriga, 49 (2010) 69-86 
do passado que resgata na epiderme das terras que emergem, são em muitos casos, desconhecidos da História e, em tantos outros, carregados de informação em sentido diverso daquela que a História reproduz.

Nesse esforço se inscreve a abertura da Arqueologia a uma multitude de especialidades de diversas origens disciplinares e o desafio que lhes lança para um debate em torno do seu objecto de estudo e da sua pesquisa e, também o trabalho colaborante com a sociedades. Esta capacidade para se construir num dialogo incessante com outras ciências e oferecer à sociedade o seu potencial como instrumento de participação activa no presente, outorgam-lhe não apenas independência disciplinar mas, também uma função social impar, no contexto das ciências Humanas e sociais.

A convenção Europeia para a Protecção do Património Arqueológico, assinada em Malta em 1992, ao consagrar a necessidade da "protecção do património arqueológico enquanto fonte da memória colectiva europeia e instrumento de estudo histórico e científico", 5 contribuiu de modo definitivo para a autonomia funcional da ciência Arqueologia e, ao definir "elementos do património arqueológico todos os vestígios, bens e outros indícios da existência do homem no passado" a cujo estudo se confere a possibilidade de "traçar a história da humanidade e a sua relação com o ambiente", definiu claramente o seu objecto de estudo a o carácter híbrido que lhe é próprio. Paralelamente, ao referir que a "principal fonte de informação é constituída por escavações ou descobertas e ainda outros métodos de pesquisa relacionados com o homem e o ambiente que o rodeia", referenciou o método e os instrumentos da Arqueologia como disciplina científica.

Os instrumentos legislativos surgem como aliados na persecução de um dos desafios intelectuais mais estimulantes do tempo presente, que é o da afirmação do valor da Arqueologia e da pertinência dos seus estudos. Ao plasmar a necessidade de implementar um conjunto de procedimentos de natureza prática, tendentes a salvaguardar o património arqueológico europeu, por este se "encontrar gravemente ameaçado de destruição em consequência tanto da multiplicação de grandes planos de ordenamento, como dos riscos naturais, de escavações clandestinas ou desprovidas de carácter científico e da deficiente informação do público" a legislação dá à Arqueologia a tarefa de "desenvolver, onde ainda sejam

\footnotetext{
Artigo $1, \mathrm{n}^{\mathrm{o}} 1$, id.

Artigo 1, $\mathrm{n}^{\mathrm{0}}$ 2, ibid.

Artigo $1, \mathrm{n}^{\mathrm{o}} 2 \mathrm{~b}$, ibid.
}

Conimbriga, 49 (2010) 69-86 
inexistentes, procedimentos adequados de supervisão administrativa e científica", e advogando que "a necessidade de proteger o património arqueológico se deveria reflectir nas políticas de ordenamento urbano e rural e de desenvolvimento cultural", aproximando as suas abordagens das de outras disciplinas.

Ao serem consagrados na lei os imperativos para recuperar, estudar e preservar o passado, os poderes, as academias e a sociedade deverão assumir o trabalho arqueológico como uma obrigação para satisfazer os desígnios da lei mas, sobretudo, como um trabalho de investigação sobre a memória e a herança colectiva dos homens onde a escavação, enquanto processo de acesso aos documentos, é uma prática determinante mas não o único método de análise da processo eco-humano de evolução das sociedades pretéritas.

A prática arqueológica actual pulsa entre dois tipos de Arqueologia: a Arqueologia programada, ou de investigação e a Arqueologia preventiva, também designada de salvaguarda.

A primeira enquadra-se em projectos científicos, cujos questionamentos pretendem alcançar respostas sobre a história das sociedades objectivando resolver problemas de natureza científica e desenvolver conhecimento. Ao mesmo tempo, ambiciona que a visibilidade do seu objecto de estudo seja potencialmente ajustável e/ou participante em projectos de desenvolvimento local ou regional.

A segunda, diferentemente da arqueologia ligada a programas de investigação, tem por vocação registar e preservar os elementos significativos do património arqueológico ameaçados por obras. Não subentende, portanto, qualquer problemática científica prévia a esse tipo de acções, actuando, por via do registo como medida para acautelar a destruição do património.

O cada vez menor investimento dos poderes públicos nos programas plurianuais de trabalhos e investigação arqueológica quase os apagou da arqueologia portuguesa; ao mesmo tempo, os grandes empreendimentos públicos e privados das últimas décadas ocupam um elevado número de arqueólogos que, à excepção de sítios que fornecem objectos ou estruturas espectaculares que escavam de modo mais sistemático, se transferem de escavação em escavação, com o trabalho constrangido às "cotas de afectação".

A arqueologia, preventiva, que representa $90 \%$ dos trabalhos arqueológicos em Portugal, prevê a intervenção dos arqueólogos antes do início de obras, permitindo, assim, assegurar a avaliação do património 
arqueológico ameaçado, proceder ao seu registo e, eventualmente, tomar medidas para a sua preservação, mas, por ser uma prática que objectiva registar o que se vê apenas em espaços a afectar, sem preocupação com um dos princípios básicos da arqueologia que é o de resgatar os testemunhos do passado para os definir totalmente e compreender no seu contexto, o seu contributo para o conhecimento é praticamente nulo.

Mesmo nos casos em que os achados exibem grande espectacularidade as escavações são quase sempre parciais e, por se conformarem numa patrimonialização de objectos e monumentos, inscrevem-se numa espécie de jogo em que o presente serve de intermediário para entregar ao futuro a responsabilidade de recuperar a memória e o conhecimento do passado que, entretanto, se registou e exibiu.

Em rigor, quase se pode afirmar, que este método, baseado no princípio da conservação pelo registo, sancionado pelo $\operatorname{art}^{\circ} 75^{\circ}, \mathrm{n}^{\mathrm{o}} 1 \mathrm{da}$ Lei n. ${ }^{\circ} 107 / 2001$, se apresenta como a transcrição para a actualidade dos procedimentos que Winckelmann, o pai da Arqueologia, no final do século XVIII, considerou deverem ser aplicados ao património arqueológico.

Entre uma Arqueologia que assume o desenvolvimento de novos questionamentos teóricos e novas metodologias, mas que não encontra meios nos poderes públicos para se afirmar e desenvolver e a prática de Arqueologia preventiva, prisioneira das cotas e dos espaços dos trabalhos de engenharia, mal posicionada para experimentar e desenvolver novas ferramentas práticas e, sobretudo participar no debate teórico que as ciências necessitam para evoluir, a arqueologia portuguesa parece não ter capacidade para acompanhar o grande desenvolvimento que a disciplina vem tendo, sobretudo, na América e América do Sul e nos países onde a Arqueologia Preventiva se organiza em torno de problemáticas científicas relacionadas com a memória e o território, recusando inscrever a sua prática num registo para ilustrar mapas de patrimonialização do espaço

Todavia, de modo algum, se pode afirmar que a Arqueologia de Investigação e a Arqueologia Preventiva se invalidem ou que tenham conciliação impossível. Em França e Itália, por exemplo, onde os laboratórios de investigação participam activamente nos projectos de obras públicas, prova-se que o conhecimento resultante dessa prática é estruturante. Em Portugal, das raras vezes em que as problemáticas arqueológicas são acolhidas no âmbito de trabalhos de engenharia e 
construção e, de acordo com a lei ${ }^{8}$, com o interesse da investigação, e também, prova-se a compatibilidade, proficuidade e o sucesso dos trabalhos e a salvaguarda de interesses.

Prova-se, ainda, a necessidade de uma nova uma epistemologia que abra novas oportunidades e permita rasgar o horizonte de possibilidades e criar alternativas à situação actual.

O projecto Arqueologia das Cidades de Beja que se desenvolve na cidade de Beja, colónia romana e capital de conventus em época romana, é prova de que os projectos de construção não são incompatíveis com os projectos científicos e que entre a Arqueologia preventiva e a arqueologia científica existem muitas outras formas de abordar o património arqueológico.

Este projecto, cujo objectivo inicial era o de aproveitar um espaço livre no centro da cidade para escavar e pesquisar vestígios da antiga cidade romana e medieval, em local onde um estudo morfológico sugeria uma riqueza construtiva ao longo dos tempos e obras levadas a cabo no início da década de quarenta do século XX haviam revelado estruturas arqueológicas que o pesquisador Abel Viana classificou como um templo romano, deparou-se, logo no início, com projectos de construção que inviabilizavam o ritmo necessário à pesquisa. Numa negociação de interesses foi, nessa altura, possível organizar e compatibilizar os trabalhos.

Os resultados dos primeiros trabalhos arqueológicos foram surpreendentes, tendo colocado em evidência um longo processo de construção da cidade, caracterizado por processos de reciclagem do espaço e dos edifícios. Os edifícios romanos eram, com funções distintas, também edifícios medievais e modernos. [Figs. 1 e 2] e nos sedimentos acumulados em profundidade de 6 e 7 metros, revelaram-se um conjunto de edifícios e ruas onde as construções romanas se utilizam como elementos da cidade no século XVIII, depois de terem feito parte dos planos urbanísticos das cidades islâmicas e medievais.

Revelaram, ainda, que a origem da cidade remontava a período anterior ao romano, algures ao século VII a. C. [Fig. 3]

A continuidade dos trabalhos haveria de nos mostrar que o edificado, de par com os restos materiais cerâmicos e outros, nos permitem ter uma imagem da dinâmica de evolução e desenvolvimento da cidade ao longo dos tempos. Nesse processo de evolução transparece a importância

8 Em concordância e respeito pelo art.5 n 1 e 2, ibid

Conimbriga, 49 (2010) 69-86 
da cidade romana e a grandeza da cidade muçulmana, forte e atractiva até ao reinado de D. Manuel, que foi Infante de Beja mas, também, o enfraquecimento do carácter cosmopolita que a caracterizava e que lhe vinham desde os tempos muito anteriores aos romanos e que, tanto quanto se pode aqui observar, parece ter-se iniciado em finais do século XVI, acentuando-se no século XVIII.

No imenso emaranhado das construções que parcialmente escavámos e que estão activas e desempenham funções distintas em tempos e sociedades, também, distintos, que por serem de vários tempos se não podem atribuir a nenhum período, destacam-se alguns edifícios, quer pelo estado de conservação, quer pelo modo como foram sendo utilizados ao longo dos tempos. [Fig. 4]

Não temos nenhuma dúvida que dois são edifícios construídos no período romano. Sem que possamos, por ora, determinar a cronologia de cada um, sabemos que se construíram em tempos distintos entre o final do séc. II a. C e meados do séc. I d. C. e que se situavam no fórum da cidade. Apesar de termos alguma suspeita, dadas as dimensões já escavadas, não podemos afirmar a exacta função destes enormes e fortes edifícios, excepto a do mais recente que, sendo um podium, de um templo integra um tanque que o rodeava em três lados. [Figs. 5 e 6]

$\mathrm{O}$ tanque rodeando um templo é um é elemento já identificado em alguns raros templos imperiais da Hispânia, como em Évora, Ecija e Barcelona, por exemplo. Porém, exceptuando Évora, em nenhum outro caso o tanque circunda o templo na totalidade, como ocorre em Pax Iulia e, também, em nenhum dos casos se escavou na totalidade ou se conservou á vista.

Este conjunto de edifícios permite-nos, finalmente, revelar estruturas de governo e administração da cidade romana e pelo modo como se articulam com as de outras sociedades posteriores, deixam aberta a possibilidade de verificar porque é que até ao século XVIII as sociedades deles fizeram uso e nessa altura deles prescindiram, bem como de toda organização urbana que então se mantinha activa. [Fig. 7]

Ao conferirmos o mesmo estatuto a todos os vestígios do passado libertámos do purgatório os objectos não datados, e acrescentámos aos objectos datados ou datáveis (normalmente a minoria), aos bonitos e de metais preciosos, uma parte substancial da documentação que era retirada da construção do discurso arqueológico. Assumimos, então, o carácter não determinante da cronologia para o conhecimento sobre o passado, ao mesmo tempo aliviámos a Arqueologia do pressuposto 
historicista que afirmava o conceito modernista de compartimentar o tempo em camadas empilhadas umas sobre as outras, correspondendo a cada uma delas uma estrutura social. Remetemos o interesse dos sedimentos do subsolo da cidade de Beja para a observação da dinâmica em espaço plurisecular e considerámos todos os participantes nessa construção como elementos portadores de elementos que em contacto com outros, ao invés de os concorrenciarem, deram origem a novos e distintos elementos. [Fig. 8]

Apreendemos, assim, todas as cidades que se sintetizam em Beja.

Observada a incapacidade do método estratigráfico, para permitir a observação dos processos evolutivos para além das suas dimensões vertical (factos diacrónicos) e horizontal (factos sincrónicos) e a sua inadequação para abordar estruturas que se enquadrem e ganhem nova função em período mais recente que aquele em que foram construídas, noutra leitura que não seja o da reutilização, fomos obrigados a encontrar um método complementar. A introdução de leituras em que se usam temporalidadades de dimensão espacio-temporal, que nos permitem acompanhar e perceber as dinâmicas dos processos de reciclagem, próprias da evolução e crescimento das sociedades num tempo longo e a reafirmação do carácter inseparável do factos ontológicos e dos factos ambientais permitiram reconhecer de modo mais exacto a complexidade do observado. $\mathrm{O}$ apelo à participação das ciências que nos permitem compreender os factos nesta dimensão onto-ecológica, foram paradigmas fundamentais e alicerçais da arqueologia que desenvolvemos neste projecto.

Numa disputa interessante entre a pertinência e exigência de coerência de continuar os trabalhos e os poderes que tutelam a arqueologia que pretendiam que se fizesse arqueologia preventiva, acabou por continuar-se o projecto. ${ }^{9}$

Nesse continuidade teve influência decisiva o incêndio que destruiu parte de edifícios municipais contíguos à escavação. A necessidade de escavar para voltar a construir abriu espaço a uma coordenação de

9 Ao mesmo tempo que os resultados dos trabalhos traziam novidade à história da colonização romana em Portugal o projecto debatia-se com sérias dificuldades para continuar. Uma decisão do IPA (instituto que tutelava a Arqueologia), sem qualquer explicação considerou os trabalhos como de Arqueologia Preventiva e cortou o financiamento ao projecto do PNTA aprovado.

Conimbriga, 49 (2010) 69-86 
vontades com a Autarquia. O desenvolvimento de um projecto conjunto de pesquisa e requalificação do local e a pesquisa ombreada de fundos para o realizar possibilitou a evolução conceptual do próprio projecto e os objectivos a que se havia proposto no início.

Aos objectivos científicos juntaram-se objectivos sociais, e o projecto científico cresceu em projecto social e de inovação. Este projecto partilhado, no qual intervêm agentes do planeamento, arquitectos, engenheiros, políticos, arqueólogos, museólogos, etc e a população, desenvolverá condições para intervir activamente na revitalização da cidade e, naturalmente, em mais um momento da sua construção.

O projecto Arqueologia das cidades de Beja no seu carácter pluridisciplinar, na multiplicidade de dimensões que se lhe reconhecem, beneficiando de uma metodologia desenvolvida para intervir em contextos complexos, nos quais se encontra inscrito o percurso das sociedades e o modo como ao longo dos tempos estas se relacionaram e recriaram na relação com o seu passado, afirma como a Arqueologia é a ciência mais preparada para ponderar o destino dos vestígios do passado, numa relação dialogante com as necessidades que as sociedades contemporâneas têm de usar o espaço, de aceder a equipamentos que permitam melhorar a sua qualidade de vida e beneficiar dos bens culturais e sociais e de participar no desenvolvimento económico.

A Arqueologia pode, por isso mesmo, proporcionar e desenvolver os interesses científicos e sociais de produção de conhecimento sobre a herança cultural, analisando-a em várias escalas espaciais e temporais, de modo a compreender a sua dinâmica de construção e daí extrair os elementos que permitam compreende-la nas temporalidades da sua realização, também, na perspectiva de uma entrega à sociedade contemporânea.

De entre os muitos caminhos que a Arqueologia vai tomando, alguns deles privilegiando as abordagens do carácter simbólico dos factos arqueológicos, outras o seu carácter funcional, existe uma arqueologia que se situa na compreensão dos processos dinâmicos que caracterizam a evolução das sociedades, atentando na dimensão híbrida dos factos que a caracterizam, na importância dos contactos e na dimensão social do património.

Arqueologia das cidades de Beja é um projecto de construção da arqueologia como uma ciência que recolhe nas terras que emergem conhecimento sobre as dinâmicas do tempo passado e, por exigência de 
coerência, o transfere para o debate sobre as políticas de planeamento e gestão do espaço do presente.

Construir o projecto de arqueologia urbana numa dimensão social de perspectiva de futuro é, ao mesmo tempo entregar às comunidades a materialidade da herança e da memória colectiva que o saber thes resgatou da epiderme do chão, que por ser por elas usado lhes pertence por direito próprio.

Conimbriga, 49 (2010) 69-86 


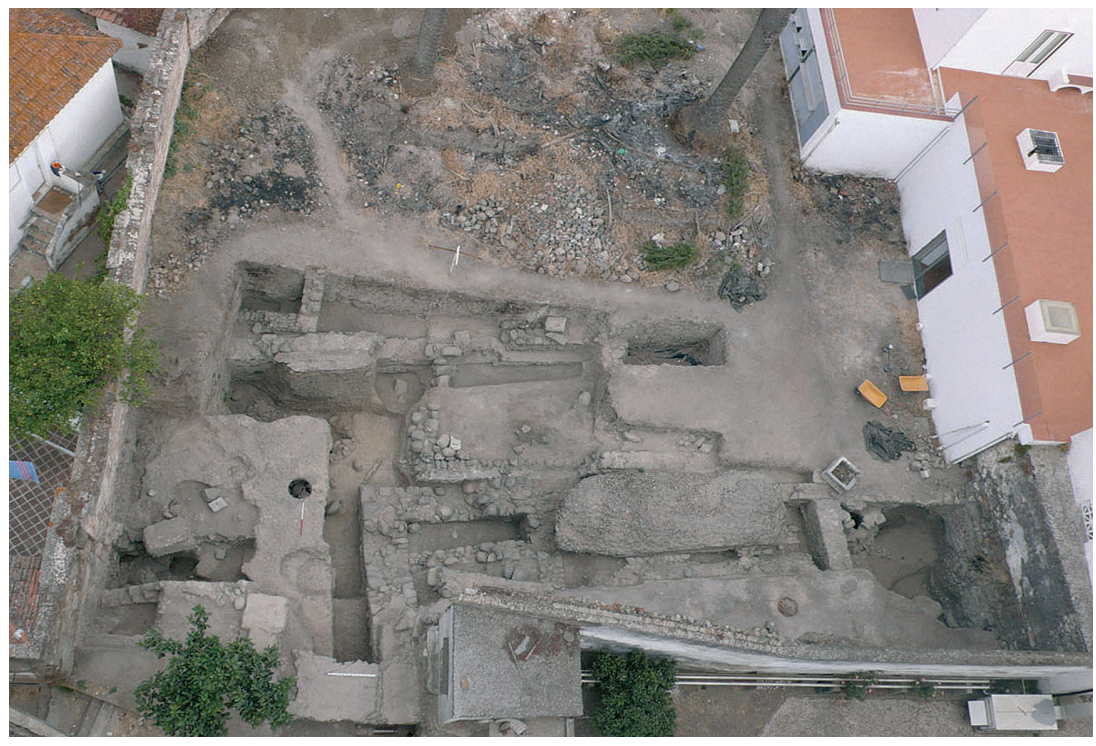

FIG. 1

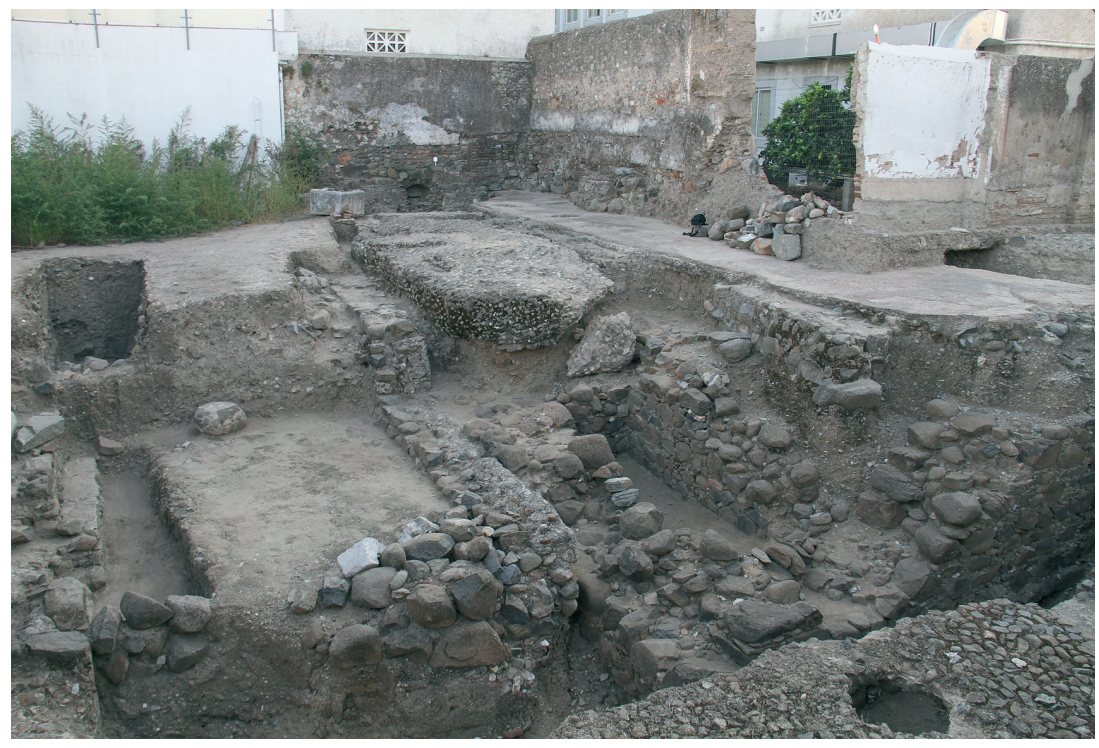

FIG. 2 


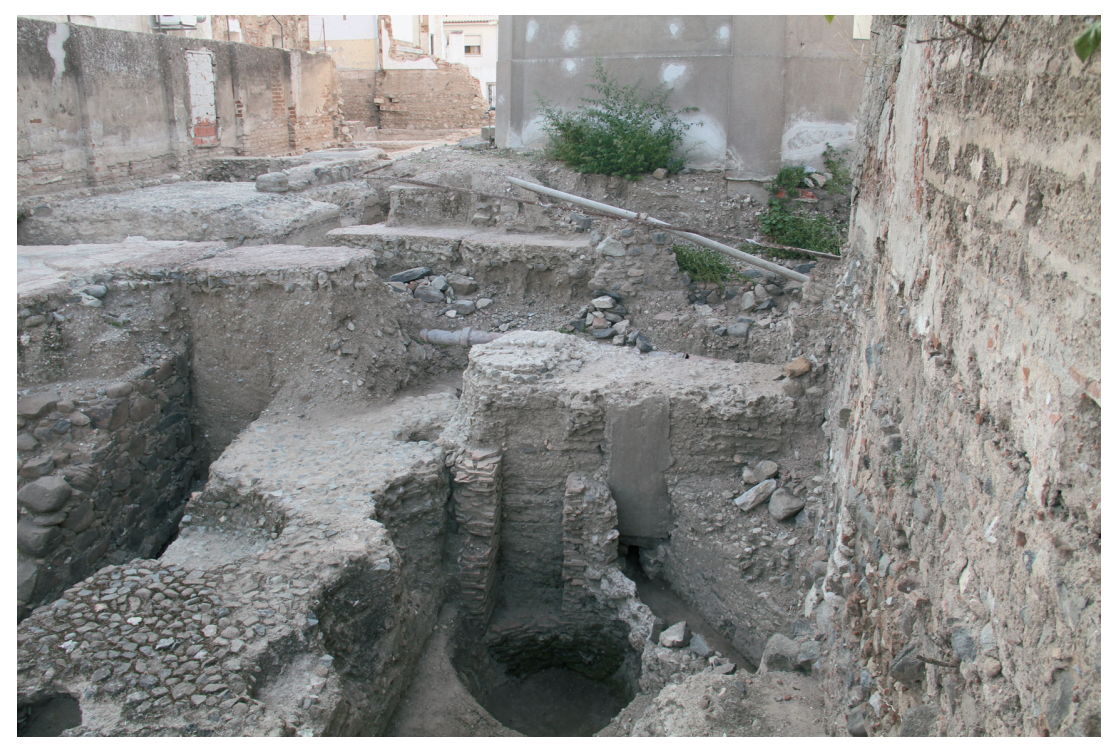

FIG. 3

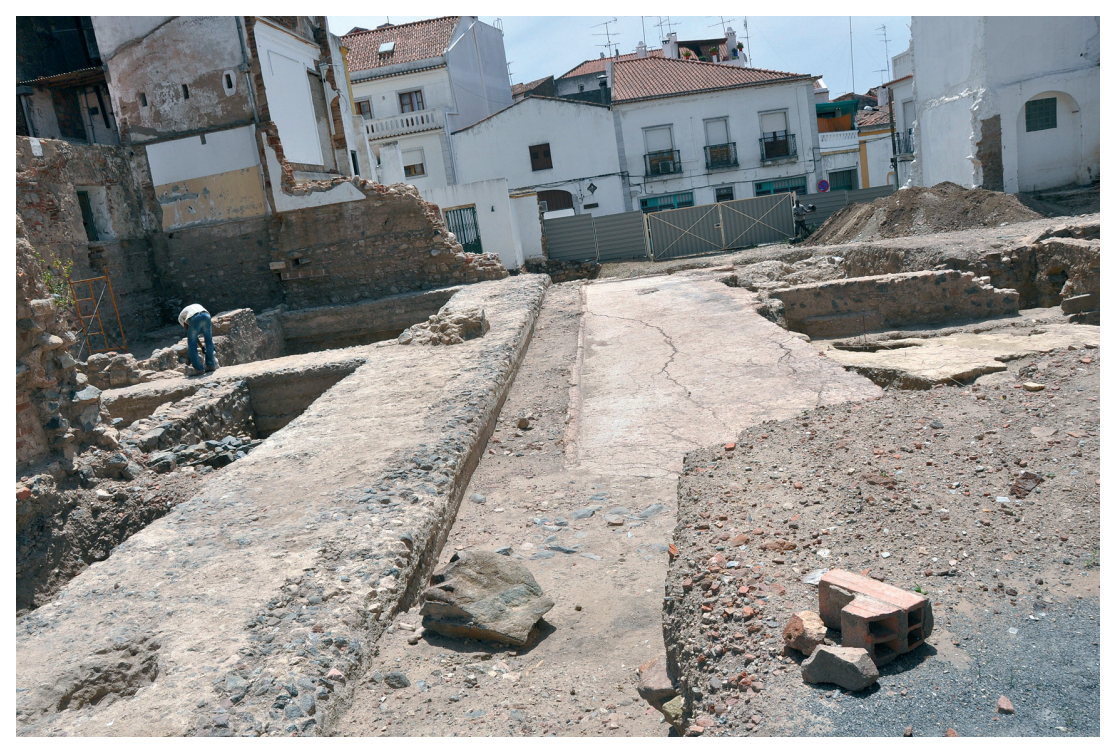

FIG. 4 


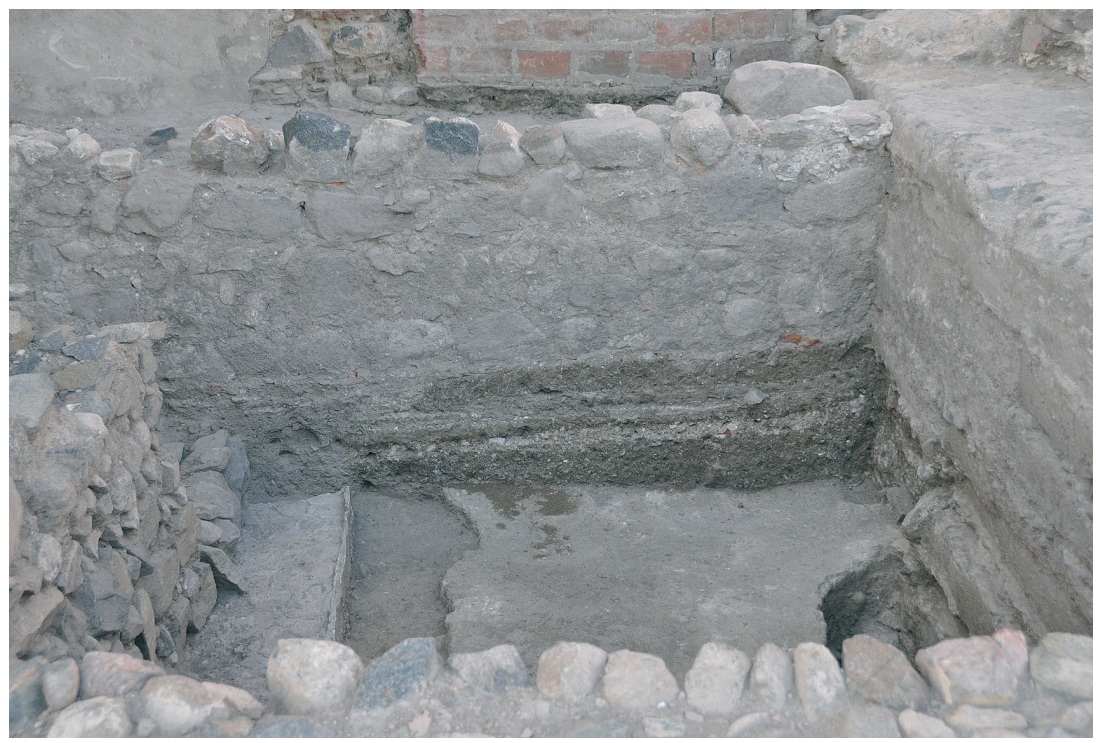

FIG. 5

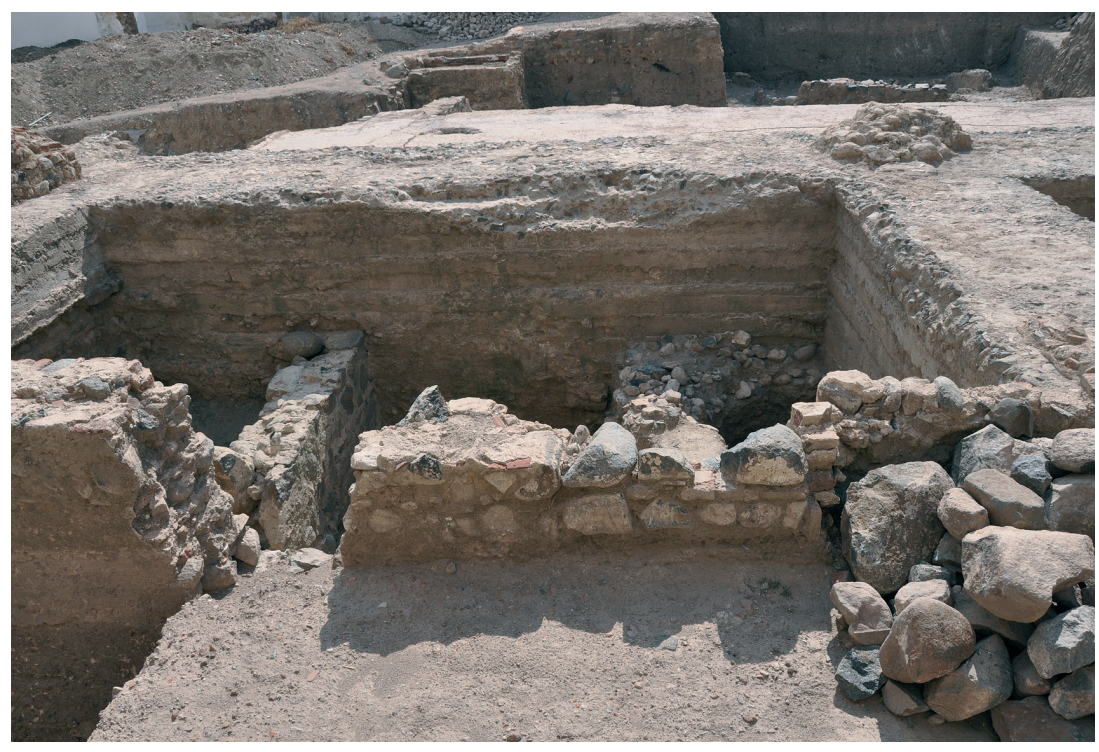

FIG. 6 


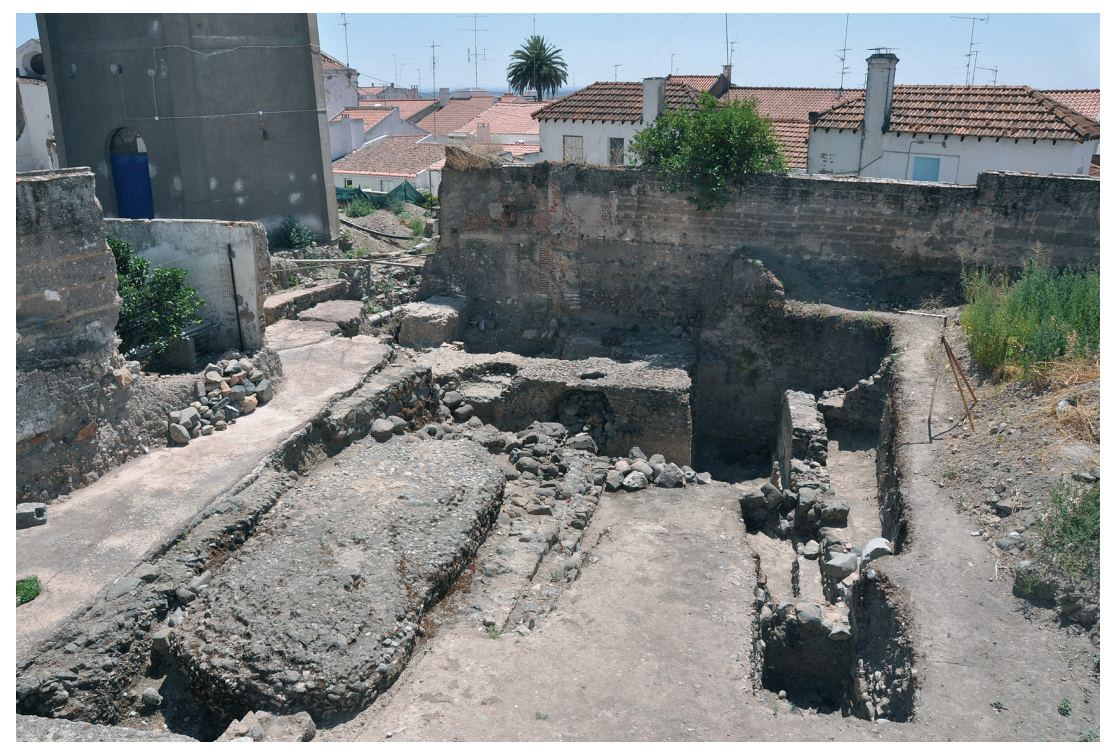

FIG. 7

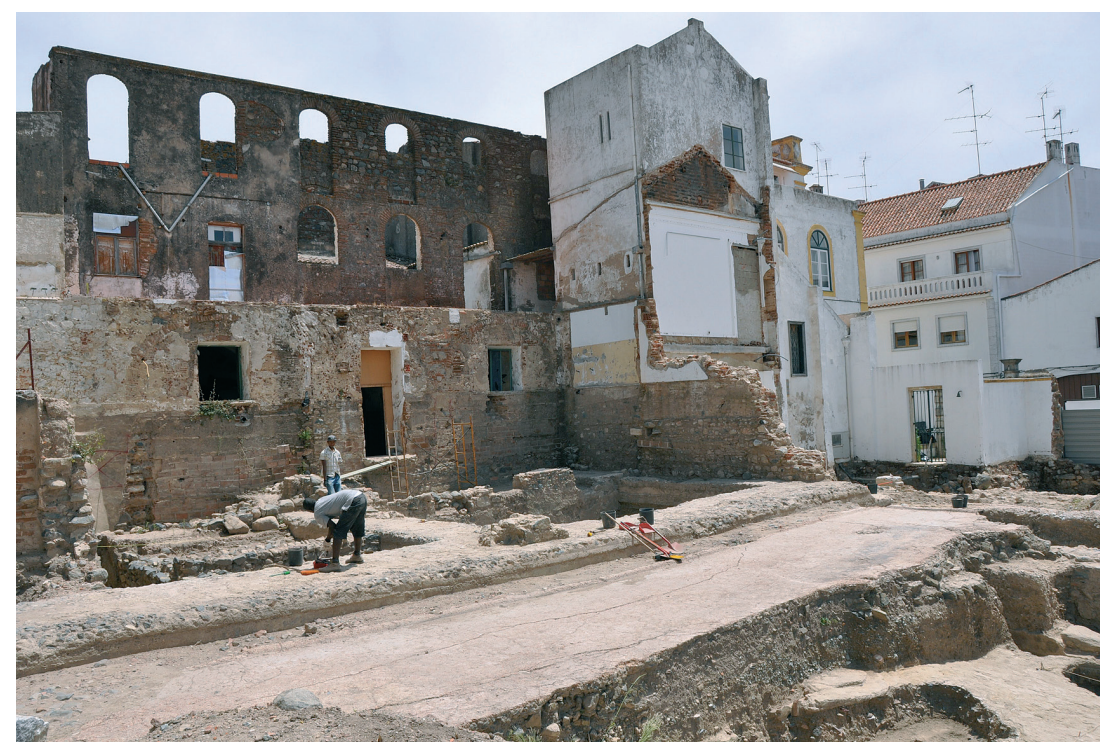

FIG. 8 